\title{
NEWS AND ANNOUNCEMENTS
}

ADSA Member News ...

\section{Funding Secured for NRC's Nutrient Requirements of Dairy Cattle; 8th ed.}

The ADSA Foundation is pleased to announce that its initiative to accelerate the update of the National Research Council's Nutrient Requirements of Dairy Cattle to an 8th edition has resulted in full funding of the NRC's estimated budget request. The ADSA Foundation committed $\$ 204,000$ (to meet the NRC's test of $51 \%$ funding from financially disinterested parties) and then secured eleven co-sponsoring organizations that committed to contributing $\$ 19,600$ each. The eleven co-sponsors are

IFEEDER (Institute for Feed Education and Research)
Zinpro Corporation
Kemin Industries
Innovation Center for U.S. Dairy
Cargill Animal Nutrition
BASF-The Chemical Company
Hubbard Feeds
Evonik Industries AG
Elanco Animal Health
Ajinomoto Heartland Inc.
Novus International Inc.

As with all previous updates of the manual, the NRC will control all aspects of the committee selection process and the development and production of the 8th edition. The innovation behind the ADSA Foundation initiative is two-fold. First, full funding was secured prior to the NRC submitting the update proposal to its Governing Board, which will allow work to begin immediately. As a result, the update will be available three to four years earlier than would otherwise be possible, benefiting the global dairy industry and consumers in a more timely manner. Second, ADSA asked the global dairy industry to provide input for the update, in the broad categories of updates, expansions/refinements, and additions. All input received by the deadline was submitted to the NRC, unedited, for the NRC to use as appropriate.

ADSA and the ADSA Foundation are proud to stand with the eleven generous co-sponsors who stepped forward to provide this incalculable benefit to the global dairy industry, from which ADSA derives support.
Positions Available . . .

The deadline for the submission of position announcements for publication in the Journal of Dairy Science is the 25th day of the month, two months preceding the month of issue. For example, ads submitted by May 25 will be printed in the July issue of the journal.

Fees for ads are based on membership in the American Dairy Science Association or the American Society of Animal Science. For members, the flat fee is $\$ 150$; for others, $\$ 250$. We do not accept display ads. Ads from agencies are not commissionable.

Position announcements should be electronically submitted, using the form on the Federation of Animal Science Societies (FASS) Web site, http://www.fass.org/job.asp, for publication in the printed version of the journal and online at the FASS Job Resource Center. Ads that appear in the printed version will automatically be posted online at no extra charge. Ads that are received past the deadline will appear only on the Web site.

If electronic submission is impossible, ads can be e-mailed to fass@assochq.org. Ads should be formatted as a single paragraph; complete sentences should be used. Advertisers will receive an invoice after the ad is posted or published; those who meet print publication deadline will receive a tearsheet with the invoice.

For more job placement announcements, please see the FASS Job Resource Center at www.fass.org/

- Assistant Professor in Animal Behavior and Well-Being. The Department of Animal Sciences at The Ohio State University has an opening for a tenure-track assistant professor in animal behavior and well-being. This position is for a 9-month, tenure-track assistant professor with an $80 \%$ extension- $20 \%$ teaching joint appointment. The extension educational program will promote best animal management practices and serve as a resource to members of the agricultural and food industries with regard to animal well-being. The faculty member will work closely with campus-based colleagues, county extension educators, area specialists, and industry toward a common goal of providing support for the state's animal industries. This will include development of fact sheets, workshops, in-service training opportunities, and participation in a community of practice. Additional expectations include teaching a course in animal behavior and well-being, contributing to other courses taught in the department, and advising undergraduate students. The new faculty member will work closely with other faculty colleagues in the Department of Animal Sciences and the College of Veterinary Medicine. Opportunity exists to address complex questions that impact the sustainability and vitality of the food animal industries in Ohio. The successful candidate would be expected to establish a novel schol- 
arly program in extension while contributing to teaching and applied research. Significant potential exists for interaction and collaboration with scientists across a large university. This position request addresses the national Food Animal Integrated Research 2012 priority of One Health.

Required qualifications include a $\mathrm{PhD}$ in animal science, animal behavior, animal ethology, or a closely related field. Documented interest and experience in one or more food animal industries is required. Applicants must have a strong interest in developing and providing extension educational programs; possess strong interpersonal and communication skills; and have the ability and desire to work with others in a collegial team environment. Leadership and academic excellence should be evident in the application. Location: Columbus Campus of The Ohio State University.

Candidates should submit a letter of application, official academic transcripts and comprehensive curriculum vitae that includes background, education, and experience. Candidate should also arrange to have three letters of recommendation sent to Dr. Henry Zerby, Department of Animal Sciences, The Ohio State University, 214 Animal Science Building, 2029 Fyffe Court, Columbus, OH 43210-1095.

Deadline is December 6, 2013, or until a suitable candidate is identified.

- Assistant Professor (with a research and teaching focus on poultry nutrition). The Department of Poultry Science, Center of Excellence for Poultry Science, University of Arkansas, Fayetteville, Arkansas, has an opening for an assistant professor (with a research and teaching focus on poultry nutrition). This is a 12-month tenure-track appointment, $80 \%$ research, $20 \%$ teaching. Salary with University of Arkansas benefits will be nationally competitive and commensurate with experience. A PhD in poultry science, nutrition, or closely related discipline is required with emphasis in poultry nutrition and biochemistry. Strong communication skills (oral and written) and the ability to procure extramural funding are required. A demonstrated excellence in publishing high impact research and developing an independent and collab- orative research program is required. Relevant poultry industry collaborations are desired.

The successful candidate will be expected to develop an innovative, internationally recognized, and extramural-funded research program in the area of poultry nutrition or biochemistry. The successful candidate's research will be directed toward improving the efficiency, yields, and health of commercial poultry. Although the specific research area is not prescribed, preference will be given to individuals with expertise in applied nutrition for industry relevance and basic nutrition for mechanistic understanding. Acceptable areas of the basic aspect of the research program include biochemical systems nutrition, metabolomics, and nutrigenomics. The applied research component will be of relevance to industry poultry nutritionists. Demonstrated research ability, effective oral and written communication, and evidence of successful grantsmanship (i.e., nationally competitive and industry funding) are essential. The successful candidate will maintain a high rate of publishing in top-ranked journals in molecular genetics and poultry science. Excellent opportunities exist for interdisciplinary and collaborative research with faculty within the department, center, college and campus.

Responsibilities include teaching, advising, and mentoring undergraduate and graduate students. Classroom instruction will be at both the undergraduate and graduate level. A key teaching component of this position is training doctoral students in poultry molecular genetics.

Applicants should submit a statement of interest, curriculum vita, academic transcripts, and names and addresses of three professional references to Dr. Michael T. Kidd, Head and Center Director, c/o Patrice Sims, O114 Department of Poultry Science, Center of Excellence for Poultry Science, 1260 West Maple Street, University of Arkansas, Fayetteville, Arkansas 72701; e-mail: Patrices@uark.edu. Position will remain open until a qualified candidate is identified. Desired starting date is July 1, 2014.

For more job position announcements, please see the FASS Job Resource Center at http:// www.fass.org/job.asp. 